\title{
Electrochemical Characterization of Iron (III) Doped Zeolite-Graphite Composite Modified Glassy Carbon Electrode and Its Application for AdsASSWV Determination of Uric Acid in Human Urine
}

\author{
Meareg Amare \\ Department of Chemistry, Bahir Dar University, Ethiopia \\ Correspondence should be addressed to Meareg Amare; amaremeareg@yahoo.com
}

Received 18 December 2018; Accepted 4 April 2019; Published 2 May 2019

Academic Editor: Valentina Venuti

Copyright (C) 2019 Meareg Amare. This is an open access article distributed under the Creative Commons Attribution License, which permits unrestricted use, distribution, and reproduction in any medium, provided the original work is properly cited.

\begin{abstract}
Iron (III) doped zeolite/graphite composite modified glassy carbon electrode was prepared for determination of uric acid in human urine samples. Electrochemical impedance spectroscopic and cyclic voltammetric results confirmed surface modification of the surface of glassy carbon electrodes. Appearance of oxidative peak current with an over threefold enhancement at significantly reduced overpotential for uric acid at the composite modified electrode relative to the unmodified and even graphite modified electrode confirmed the electrocatalytic property of the composite towards electrochemical oxidation of uric acid. Under optimized method and solution parameters, linear dependence of peak current on uric acid concentration in a wide range of 1-120 $\mu \mathrm{M}$, low detection limit value $(0.06 \mu \mathrm{M})$, replicate results with low RSD, and excellent recovery results $(96.61-103.45 \%)$ validated the developed adsorptive anodic stripping square wave voltammetric (AdsASSWV) method for determination of uric acid even in aqueous human urine samples. Finally, the developed composite modified electrode was used for determination of uric acid content in human urine samples collected from three young male volunteers. While the uric acid level in the urine samples from two of the studied volunteers was within the normal range, of the third was under the normal range.
\end{abstract}

\section{Introduction}

Uric acid (2,6,8-trioxypurine) (Scheme 1) is a compound endogenously produced by animals as a purine metabolite. It is the end product of purine metabolism in humans due to the loss of uricase activity making humans have higher uric acid (UA) level than other mammals [1,2]. UA is produced by the liver leading to normal uric acid concentration of 3.4-7.2 for men and $2.4-6.1 \mathrm{mg} / \mathrm{dL}$ of plasma for women which ultimately is excreted chiefly by the kidneys (65$75 \%)$ and intestines (25-35\%) $[1,2]$. Due to its excellent antioxidant character, UA is the major contributor for the total antioxidant capacity of plasma in human body [3]

As high UA content in body fluids may cause several diseases including gout, kidney diseases, hypertension, and cardiovascular diseases, lower UA level equally provokes diseases like multiple sclerosis, Parkinson's disease, Alzheimer's disease, and optic neuritis [3-6]. Thus, development of a simple, rapid, and sensitive method for continual monitoring of its level in human body fluids including urine is vital. A range of techniques including chromatography [7, 8], electrophoresis $[9,10]$, potentiometry [11], spectroscopy [12], and amperometry [13] have been reported for determination of UA in different samples.

In spite of all these efforts made, these methods still remained laborious and time-consuming, require sophisticated equipment, and are expensive, which make them unsuitable for rapid detection and restrain their wide applications [14]. Taking into consideration the fact that electrochemical methods are fast, sensitive, less expensive, and environmentally friendly, these methods have received much attention for determination of uric acid regardless of the matrix type. Although several works have been reported on the electrochemical determination of uric acid [15-21], the development of modified electrode which is more stable, easy to prepare, sensitive, and relatively of low cost is still 


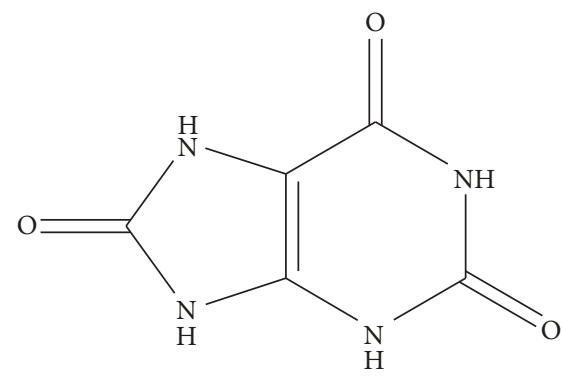

SCHEME 1: Structural formula of uric acid.

important. While few works on application of metal doped zeolite-modified glassy carbon electrodes have been reported, to the best of our knowledge $\mathrm{Fe}(\mathrm{III})$ impregnated zeolitegraphite composite modified glassy carbon electrode (FeZG/GCE) for determination of uric acid in human urine has not been reported.

The superior features of zeolite-modified electrodes (ZMEs) for catalysis and analytical application over other modifiers arise from the joined size selectivity and ionexchange capacity of zeolite molecular sieves [22].

Thus, the aim of this paper was to characterize the FeZ-G/GCE using cyclic voltammetry and electrochemical impedance spectroscopy, investigate the electrochemical behavior of uric acid at the modified electrode, and further evaluate the applicability of the developed adsorptive anodic stripping square wave voltammetric (AdsASSWV) method for determination of uric acid in urine even in the presence of ascorbic acid.

\section{Experimental}

2.1. Chemicals and Reagents. Chemicals and reagents are sodium Y zeolite powder ( $>90 \%$ particle size, Merck), anhydrous ferric chloride (99.99\%, Merck), graphite powder (Blulux Laboratories (p) Ltd.), polystyrene (Merck), dichloromethane (99.9\%, CARLO ERBA reagents), tetrahydrofuran (99.5\%, Blulux laboratories (p) Ltd), paracetamol (Sigma-Aldrich, Germany), uric acid (99.0\%, Labort Fine Chem Pvt Ltd), ascorbic acid (99.0\%, Merck), orthophosphoric acid (85.74\%, Fisher Scientific), potassium dihydrogen orthophosphate $(99.0 \%$, Titan Biotech Ltd), dipotassium hydrogen orthophosphate (99.0\%, Titan Biotech Ltd), and potassium nitrate (>99.0\%, Merck). All chemicals and reagents were of analytical grade and hence were used without prior purification.

2.2. Apparatus and Instruments. CHI 760d Electrochemical Workstation (Austin, Texas, USA), ultrasonicator (Indiamart), $\mathrm{pH}$ meter (Adwa instruments kit), balance (Nimbus ThermoFisher Scientific), and Eppendorf tube were among the instruments and apparatus used.

2.3. Electrochemical Measurements. In both the voltammetric and electrochemical impedance spectroscopic analyses, a conventional three-electrode system was employed with a bare GCE (3 $\mathrm{mm}$ in diameter), graphite modified glassy carbon electrode (GGCE), or iron (III) doped zeolite/graphite composite modified glassy carbon electrode (FeZGC/GCE) as working electrode, silver/silver chloride $(\mathrm{Ag} / \mathrm{AgCl})$ as reference electrode, and platinum coil as a counterelectrode.

While cyclic voltammetry was used to investigate the electrochemical behavior of uric acid at the unmodified and modified glassy carbon electrodes, effect of scan rate on oxidative peak current and dependence of both the oxidative peak current and peak potential of UA at the surface of the composite modified glassy carbon electrode on $\mathrm{pH}$; square wave voltammetry under default square wave parameters (amplitude $25 \mathrm{mV}$, step potential $4 \mathrm{mV}$, and frequency $25 \mathrm{~Hz}$ ); and optimized deposition parameters $\left(\mathrm{E}_{\mathrm{acc}}\right.$ of $-0.1 \mathrm{~V}$ and $\mathrm{t}_{\mathrm{acc}}$ $30 \mathrm{~s}$ ) were used for the determination of UA in human urine samples collected from three volunteers. The electrochemical impedance spectroscopic behavior of the assessed working electrodes was also investigated using $10 \mathrm{mM} \mathrm{Fe}(\mathrm{CN})_{6}^{3-} /^{4-}$ in $0.1 \mathrm{M} \mathrm{KCl}$ as a probe.

\subsection{Solution and Sample Preparation}

2.4.1. Standard Solution Preparation. $100 \mathrm{ml}$ of $10 \mathrm{mM}$ stock solution of UA in $\mathrm{pH} 7.0$ of $0.1 \mathrm{M}$ phosphate buffer solution (PBS) was prepared from which $1 \mathrm{mM}$ working solutions of UA in PBS of various pHs were prepared. Standard working solutions of UA in $\mathrm{pH}$ 7.0 PBS were also prepared by serial dilution from the stock solution for calibration curve.

2.4.2. Human Urine Sample Preparation. Three human urine samples designated as " $A$," "B," and " $C$ " were collected from three young male volunteers using cleaned plastic bottles. After the samples were centrifuged for $10 \mathrm{~min}$ at $4000 \mathrm{rpm}$, $50 \mathrm{~mL}$ of urine solution was prepared for each urine sample by putting $1 \mathrm{~mL}$ of the centrifuged urine in a volumetric flask and diluted to the mark with $\mathrm{pH}$ 7.0. The diluted urine solutions were kept in a refrigerator until analysis.

2.5. Electrode Preparation. Glassy carbon electrode of $3 \mathrm{~mm}$ disc diameter was made ready for use as bare or modified after being polished successively with alumina powder of 1.0, 0.3, and $0.05 \mu \mathrm{m}$ course size.

A mixture of $50 \mathrm{mg}$ of graphite powder and $5 \mathrm{mg}$ of polystyrene as a binder was dispersed in $250 \mu \mathrm{L}$ solution of tetrahydrofuran and dichloromethane (2:3 volume ratio). A $2 \mathrm{~mL}$ Eppendorf tube containing the mixture was first handshaken for five minutes and then sonicated for two minutes in ultrasonic water bath. The graphite modified glassy carbon electrode (G/GCE) was prepared by casting $10 \mu \mathrm{L}$ of the suspension on the surface of a mirror-like cleaned glassy carbon electrode and air-dried before use.

The iron (III) doped zeolite-graphite composite modified glassy carbon electrode (FeZ-G/GCE) was prepared following reported procedure with minor modification [21]. Briefly, lightly ground $1 \mathrm{~g}$ of zeolite y using a mortar and pastel was added to $250 \mathrm{~mL}$ of $0.01 \mathrm{M} \mathrm{FeCl}_{3}$ in deionized water and stirred with a magnetic stirrer at $2000 \mathrm{rpm}$ for $48 \mathrm{hrs}$. The iron exchanged zeolite was then collected as a 


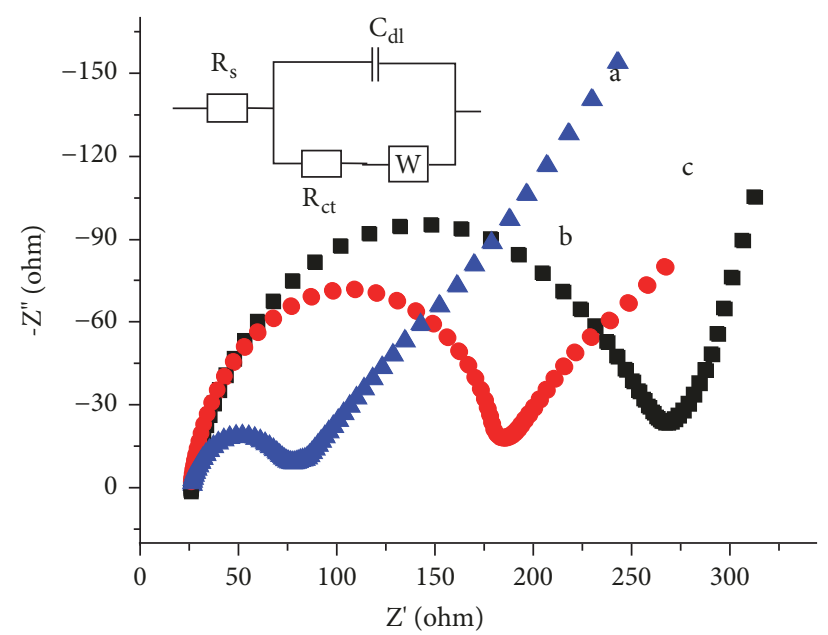

FIgUre 1: EIS Nyquist plot of (a) UGCE, (b) GGCE, and (c) FeZG/GCE in $0.1 \mathrm{M}$ PBS (pH 7) containing $10 \mathrm{mM} \mathrm{Fe}(\mathrm{CN})_{6}^{3-} /^{4-}$ and $0.1 \mathrm{M} \mathrm{KCl}$ supporting electrolyte. Frequency range: $1.0-100,000 \mathrm{~Hz}$; applied potential: $+0.23 \mathrm{~V}$; amplitude: $0.01 \mathrm{~V}$. Inset: proposed equivalent circuit for the three studied electrodes.

residue by discarding the supernatant. The collected modified zeolite was carefully washed with $\mathrm{HCl}$ solution ( $\mathrm{pH}$ of 2.0 ) to remove occluded materials and surface-adherent salts and then washed with distilled water until it is chloride-free. A loosely ground mixture of $50 \mathrm{mg}$ of air-dried exchanged zeolite and $50 \mathrm{mg}$ of graphite powder was put in $5 \mathrm{~mL}$ tight Eppendorf tube to which $10 \mathrm{mg}$ of polystyrene was added. $250 \mu \mathrm{L}$ of tetrahydrofuran and $350 \mu \mathrm{L}$ of dichloromethane were added to the tube, hand-shaken for 5 minutes, and further sonicated for three minutes. Finally, FeZ-G/GCE was prepared by casting $10 \mu \mathrm{L}$ of the suspension on the surface of a well-polished GCE and dried in air for about 30 minutes. The modified electrode was then activated by scanning it in a $0.5 \mathrm{M} \mathrm{KCL}$ in $\mathrm{pH} 7 \mathrm{PBS}$ between -0.3 and $1.1 \mathrm{~V}$ until well-shaped characteristic peaks for $\mathrm{Fe} 3+/ \mathrm{Fe} 2+$ appeared. The activated electrode is then prepared for use after scanning it in the buffer until stable wave is created.

\section{Results and Discussion}

\subsection{Characterization of Iron (III) \\ Doped Zeolite/Graphite Composite Modified GCE}

3.1.1. Electrochemical Impedance Spectroscopic Characterization. The Nyquist plots for the investigated working electrodes under similar conditions are presented in Figure 1. As can be seen from the figure, all electrodes possess semicircles of different diameters associated with lines at 45 degrees. While the lines at 45 degrees depict diffusion of the electroactive species, the different semicircle diameters represent different charge transfer resistance and double layer capacitance. A semicircle with wider diameter for the composite modified electrode (curve c of Figure 1) than the graphite modified (curve b) and the unmodified glassy carbon electrode (curve a) indicated modification of the electrode surface with a material whose resistance to charge transfer is higher. An equivalent circuit (Inset of Figure 1) with charge transfer resistance $\left(\mathrm{R}_{\mathrm{ct}}\right)$ and Warburg constant $(\mathrm{W})$ in series was proposed for the three electrodes. The result showed that the electrodes are different confirming the composite modification of the electrode.

3.1.2. Cyclic Voltammetric Characterization. Figure 2(a) depicts the cyclic voltammograms of the composite modified glassy carbon electrode at various scan rates. Appearance of a pair of peaks in the potential range 0.2 to $0.8 \mathrm{~V}$ at all scan rates confirmed the incorporation of $\mathrm{Fe}^{3+}$ into the cavities of zeolite. Comparable correlation coefficients for the linear dependence of the peak current on the square root of scan rate (Figure 2(b)) and scan rate (Figure 2(c)) showed that the redox reactions were influenced by both diffusion of the electroactive species $\left(\mathrm{Fe}^{2+} / \mathrm{Fe}^{3+}\right)$ from distant to the surface of the electrode where electron exchange is taking place and adsorption of the same species just at the surface. While the diffusion phenomena could be ascribed to the diffusion of the $\mathrm{Fe}^{3+}$ species from the cavities of zeolite to the surface and of the formed $\mathrm{Fe}^{2+}$ back to the cavities, the adsorption phenomena could be explained as the back and forth mass transfer of the electroactive species just from the surface $[21,23]$.

\subsection{Electrochemical Behavior of Equimolar Mixture of UA and} $A A$ at Different Electrodes. To evaluate the selectivity and catalytic property of the composite modified electrode for UA relative to the graphite modified and unmodified glassy carbon electrodes, cyclic voltammograms of each electrode were recorded for blank, UA, AA, and equimolar mixture of UA and AA (Figure 3).

Although relative peak current enhancement was observed at the GGCE for both the UA and AA, both electrodes were unable to detect UA and AA, separately (Figures 3(a) and 3(b)) which of course is in agreement with previously reported works [24]. On the contrary, the FeZ-G/GCE revealed well-resolved (separated) oxidative peaks with better current enhancement and overpotential reduction for AA and UA. Surprisingly, a reductive peak for UA was observed (peak $2^{\prime}$ of Figure 3(c)) at the FeZG/GCE which is absent not only at the UGCE and GGCE we studied but also at other reported modified electrodes. This observed electrocatalytic activity of the composite modifier may be attributed to the improved electron exchange and increased surface area. The electrocatalytic property of the composite modified electrode demonstrated by peak current enhancement, lowering of overpotential, separate peaks for AA and UA, and rise of an oxidative peak for UA confirmed superior candidacy of the iron doped zeolite/graphite composite modified glassy carbon electrode for determination of UA in real samples even in the presence of AA.

3.3. Effect of Scan Rate. Sharp and intensive oxidative peaks for UA and weak peaks for AA with peak potential shift in the positive direction with scan rate (Figure 4(a)) confirmed the irreversibility of the oxidation reaction of UA at the surface of the modified electrode. 


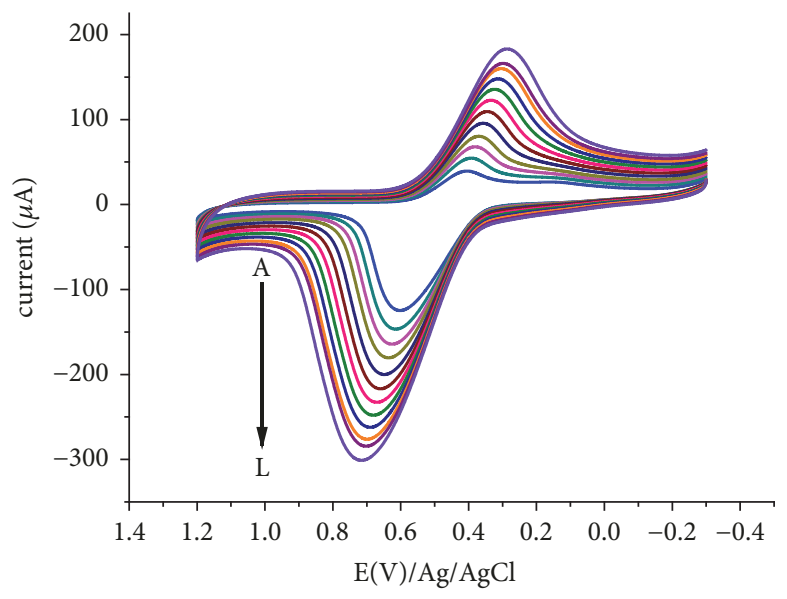

(a)

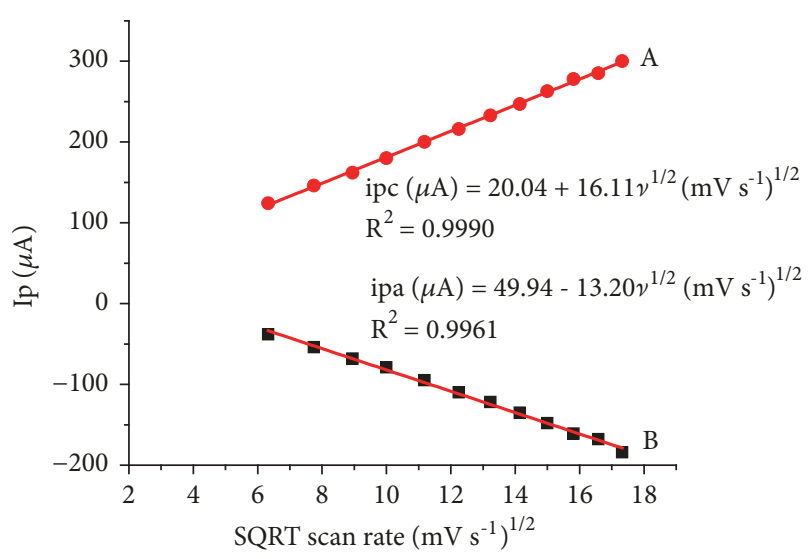

(b)

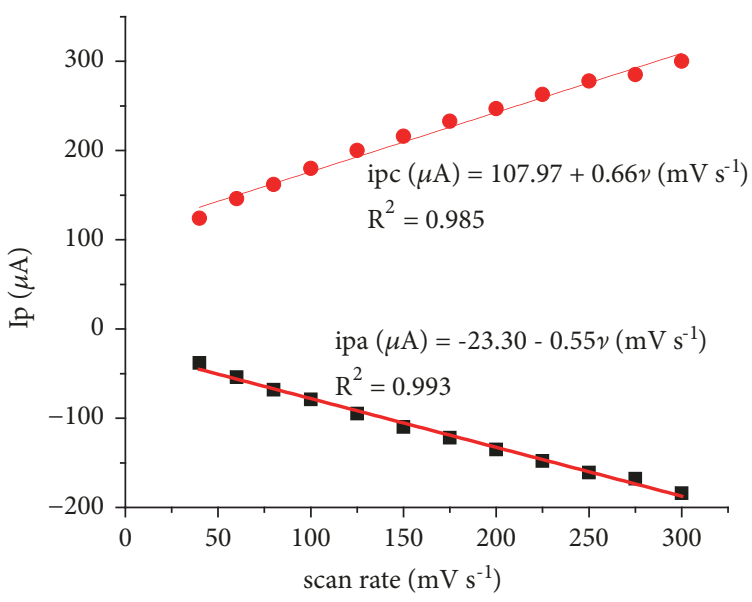

(c)

Figure 2: Cyclic voltammograms of stabilized FeZ-G/GCE in $0.5 \mathrm{~mol} \mathrm{~L}^{-1} \mathrm{KNO}_{3}$ (in pH 7 PBS) at different scan rates (A-L: 40, 60, 80, 100, $125,150,175,200,225,250,275$, and $300 \mathrm{mV} \mathrm{s}^{-1}$, respectively) (a); plot of peak current (Ip) $v s$ square root of scan rate (b) and scan rate (c).

As can be seen from Figure 4(b), the peak current for both analytes is linearly related more with the scan rate than the square root of scan rate confirming the dominance of adsorption mass transport over diffusion. To further confirm the adsorption controlled oxidation reaction of UA, cyclic voltammograms of $1 \mathrm{mM}$ UA in the presence of $1 \mathrm{mM}$ AA were monitored at quite times 2 to $32 \mathrm{~s}$ (Figure 5). The oxidative peak current of UA at quite time of $7 \mathrm{~s}$ was found to be over $100 \%$ of the current at quite time of $2 \mathrm{~s}$ (Inset of Figure 5). Although the increment is lowered, still oxidative current increased with increasing quite time (time of exposure of the electrode surface to the analyte solution) confirming the adsorption controlled mechanism proposed above.

3.4. Effect of $p H$. To evaluate the effect of $\mathrm{pH}$ on the peak current and peak potential, cyclic voltammograms of the modified electrode in $\mathrm{PBS}$ in the $\mathrm{pH}$ range of 4.5 to 9.0 containing a mixture of $1 \mathrm{mM}$ UA and $1 \mathrm{mM}$ of AA were recorded (Figure 6(a)).
Whereas the oxidative peak potential of UA shifted in the positive potential direction leading to increased overpotential when $\mathrm{pH}$ is varied from 4.5 to 6.0 (Inset of Figure 6(a)), potential shift in the reverse direction and hence decreasing overpotential is noticed with increasing $\mathrm{pH}$ values from 6.0 to 9.0. This trend could still be ascribed to the type and magnitude of charges the surface of the electrode and analyte develop with $\mathrm{pH}$. This observed peak potential shift with $\mathrm{pH}$ variation confirmed the participation of protons during the oxidation of UA at the surface of the composite modified electrode.

The peak current increased with $\mathrm{pH}$ from $\mathrm{pH} 4.5$ to 7.0 and then started to decline at values higher than 7.0 (Figure $6(\mathrm{~b})$ ) demonstrating the participation of protons during oxidation of UA at the electrode surface. This trend could be ascribed to the electrostatic repulsion exerted between the positive charged zeolite due to the incorporated $\mathrm{Fe}^{3+/ 2+}$ and protonated UA ( $\mathrm{pKa}=5.4$ ) whose strength decreases with increasing $\mathrm{pH}$ and the deprotonated zeolite and UA at higher $\mathrm{pH}$ values. Thus, $\mathrm{pH} 7.0$ was taken as the optimum $\mathrm{pH}$ value 


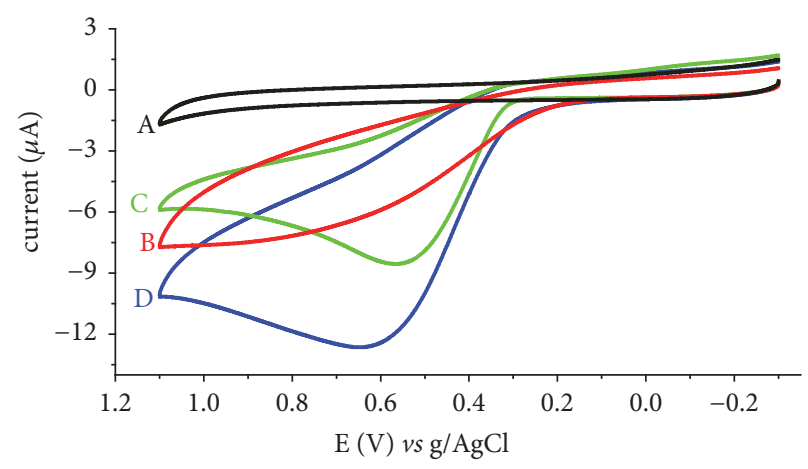

(a)

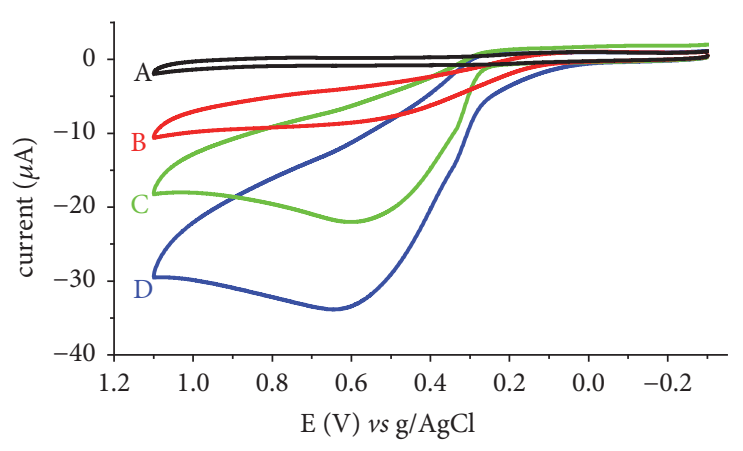

(b)

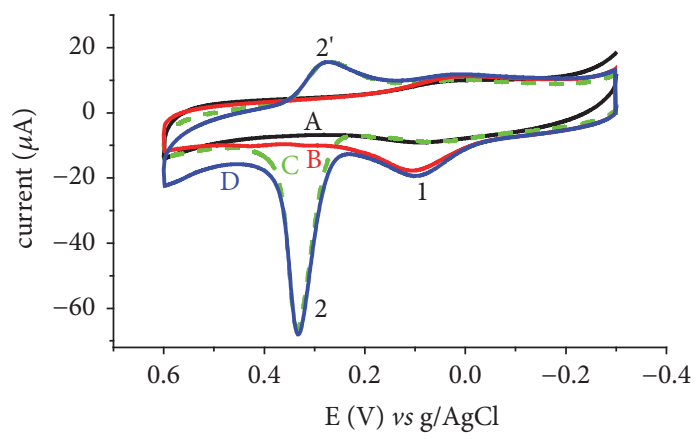

(c)

FIgURE 3: Cyclic voltammograms of (a) UGCE, (b) GGCE, and (c) FeZ-G/GCE in pH 7.0 PBS containing (A) no analyte, (B) 1 mM AA, (C) $1 \mathrm{mM} \mathrm{UA}$, and (D) mixture of $1 \mathrm{mM} \mathrm{AA}$ and $1 \mathrm{mM} \mathrm{UA}$ at a scan rate of $100 \mathrm{mV} \mathrm{s}^{-1}$.

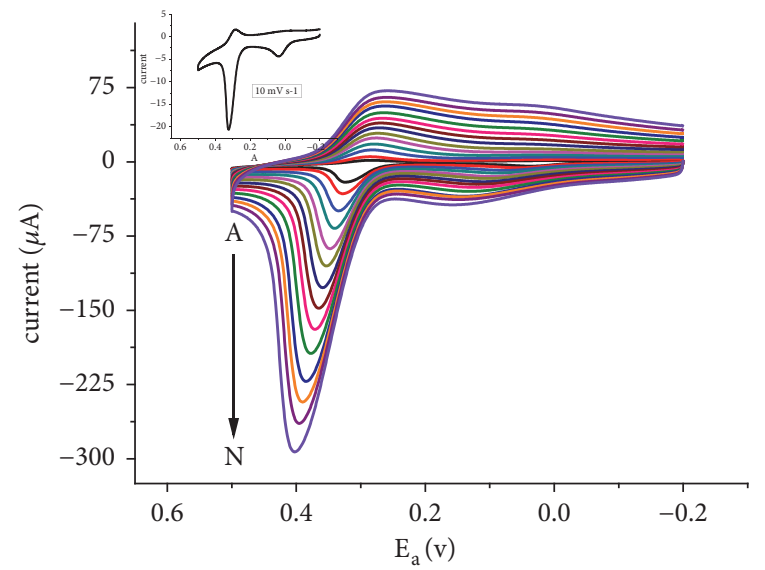

(a)

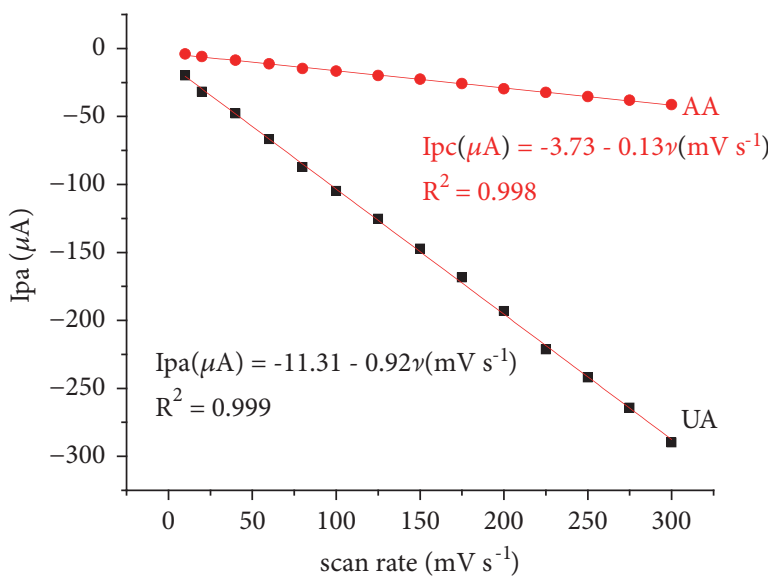

(b)

Figure 4: Cyclic voltammograms of a mixture of $1 \mathrm{mM} \mathrm{UA}$ and $1 \mathrm{mM}$ AA pH 7.0 PBS at different scan rates (A-N: 10, 20, 40, 60, 80, 100, 125, $150,175,200,225,250,275$, and $300 \mathrm{mV} / \mathrm{s}$, respectively) (a) and plot of peak current response for AA and UA against scan rate (b). Separated cyclic voltammogram of the same at scan rate of $10 \mathrm{mV} \mathrm{s}^{-1}$ (Inset of (a)).

where maximum current for uric acid can be recorded at the surface of the FeZ-G/GCE.

\subsection{Determination of UA Content in Human Urine Sample.} Due to its sensitivity and ability to discriminate Faradaic from non-Faradaic current, square wave voltammetry was selected for the determination of UA in human urine. As depicted from Figure 7, a well-shaped voltammogram with an intense corrected oxidative peak current response at default parameters confirmed the applicability of SWV for the analysis of uric acid.

3.5.1. Influence of Accumulation Potential and Time. The observed dominance of adsorption over diffusion necessitated investigation of the effect of the adsorption potential and adsorption time on the oxidative peak current of UA. 


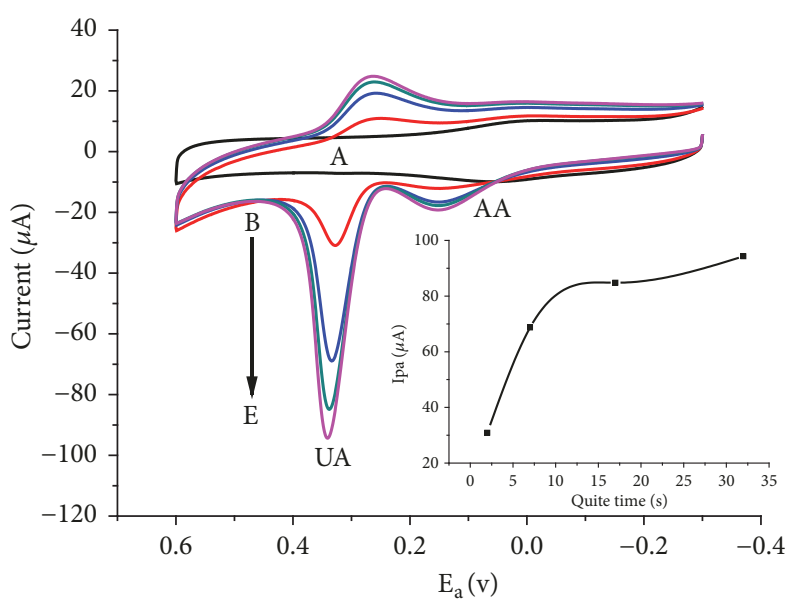

Figure 5: Cyclic voltammograms of FeZ-G/GCE pH 7 PBS containing (A) no UA and AA at a quite time of $2 \mathrm{~s}$ (A) and (B-E) containing $1 \mathrm{mM}$ of $\mathrm{UA}$ and $1 \mathrm{mM}$ of AA at various quite times (B-E: 2, 7, 17, and $32 \mathrm{~s}$, respectively).

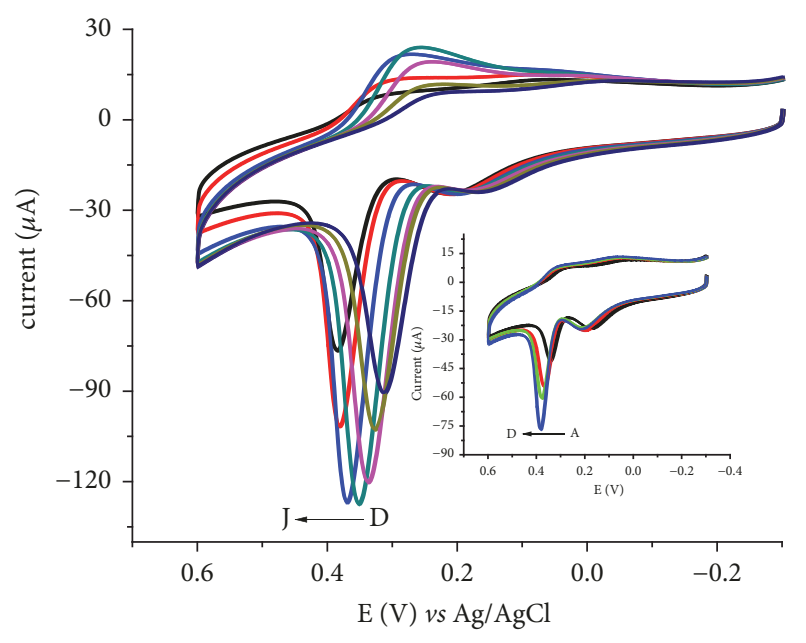

(a)

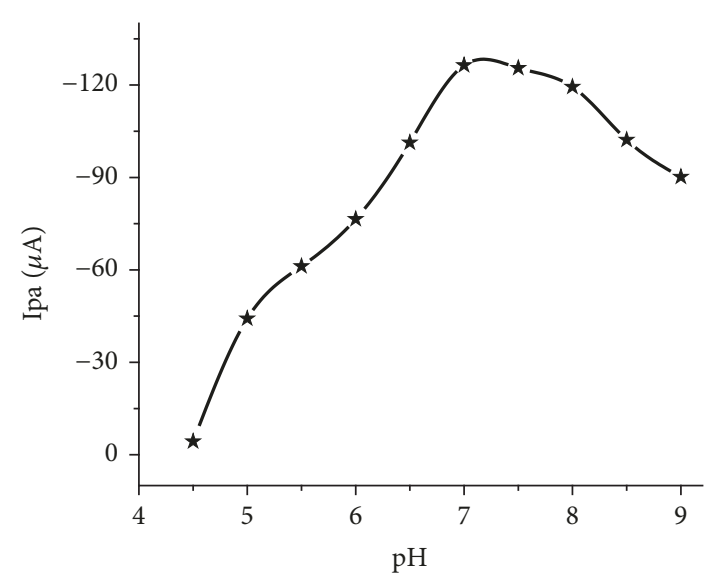

(b)

FIGURE 6: (a) Cyclic voltammograms of PBS of various pHs (D-J: 6.0, 6.5, 7.0, 7.5, 8.0, 8.5, and 9.0, respectively) containing $1 \mathrm{mM}$ UA in the presence of $1 \mathrm{mM}$ AA. Inset: voltammograms of $1 \mathrm{mM}$ UA and $1 \mathrm{mM}$ AA in PBS of pHs (A-D: 4.5, 5.0, 5.5, and 6.0, respectively). (b) Plot of peak current of UA against $\mathrm{pH}$ in the range 4.5-9.0.

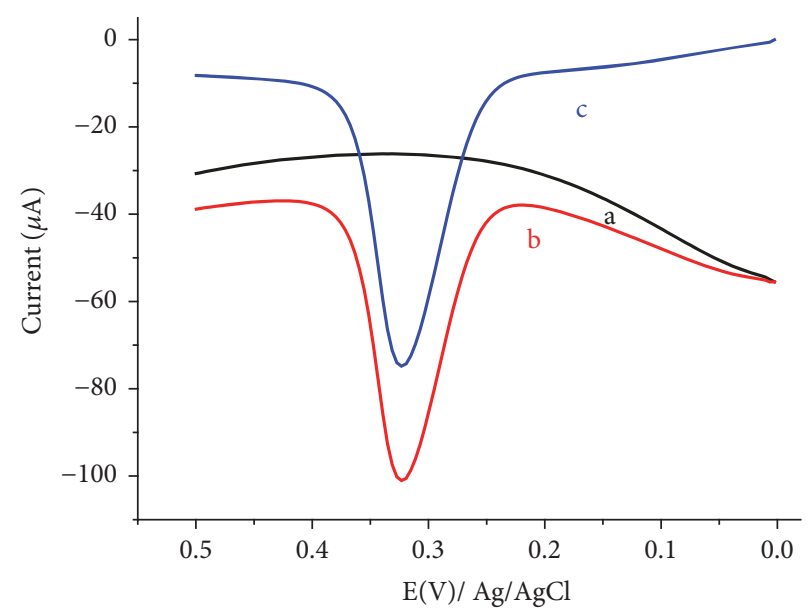

FIGURE 7: Square wave voltammograms of FeZ-G/GCE in pH 7 PBS containing (a) no UA, (b) 1 mM UA, and (c) corrected for blank (curve $b$ and curve a). 


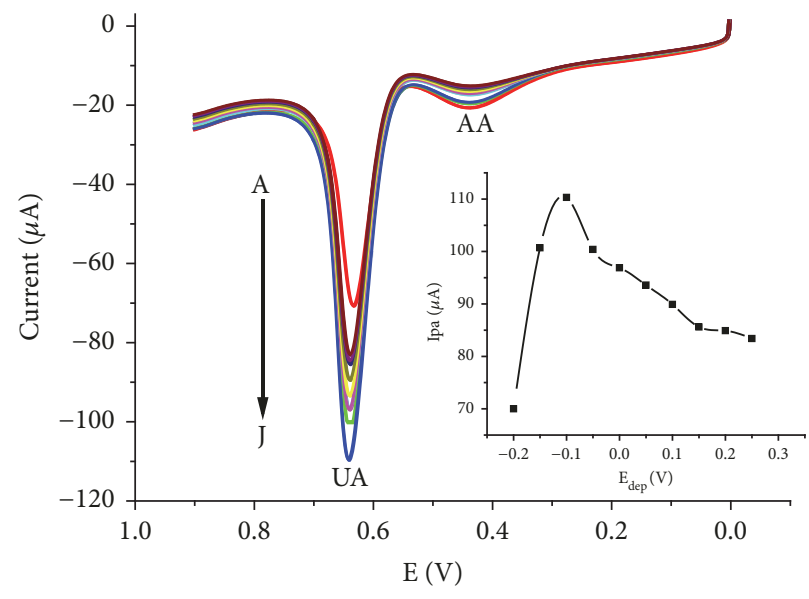

(a)

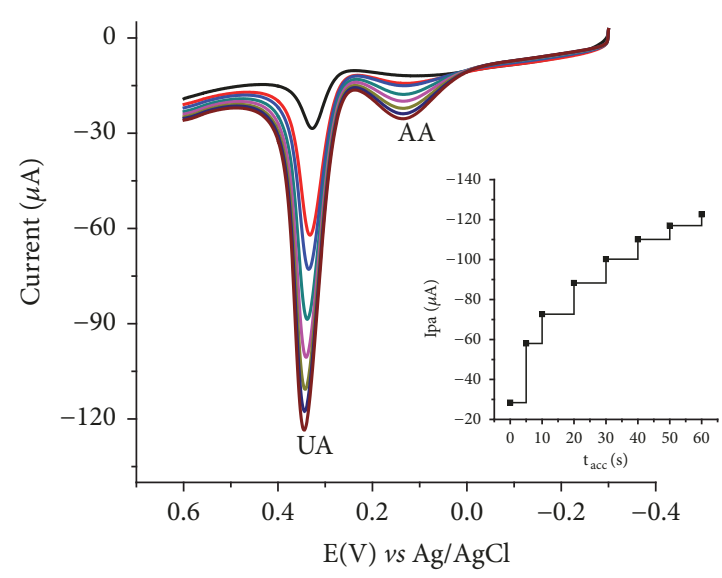

(b)

FIGURE 8: Square wave voltammograms of a mixture of $1 \mathrm{mM} \mathrm{UA}$ and $1 \mathrm{mM} \mathrm{AA}$ in pH 7 PBS at (a) $\mathrm{E}_{\mathrm{acc}}$ of -200 to $+250 \mathrm{mV}$ and $\mathrm{t}_{\mathrm{acc}}$ of $10 \mathrm{~s}$, (b) $\mathrm{E}_{\mathrm{acc}}$ of $-100 \mathrm{mV}$ and $\mathrm{t}_{\mathrm{acc}}$ of 0 to $80 \mathrm{~s}$, plot of peak current versus $\mathrm{E}_{\mathrm{acc}}$ (Inset (a)), and plot of peak current versus $\mathrm{t}_{\mathrm{acc}}$ (Inset (b)).

TABLE 1: Summary of uric acid content in human urine samples collected from three volunteers.

\begin{tabular}{|c|c|c|c|c|}
\hline Urine sample & $\begin{array}{l}\text { Current* } \\
\qquad(\mu \mathrm{A})\end{array}$ & Current $(\bar{X} \pm R S D) /(\mu \mathrm{A})$ & $\begin{array}{c}\text { Mean UA } \\
\text { concentration in } \\
\text { human urine }(\mu \mathrm{M})\end{array}$ & $\begin{array}{l}\text { UA content in } \mathrm{mg} / 100 \text { human } \\
\text { urine sample } \\
(\bar{X} \pm R S D)\end{array}$ \\
\hline \multirow{3}{*}{ A } & 0.615 & \multirow{3}{*}{$0.625 \pm 0.014$} & \multirow{3}{*}{132.9} & \multirow{3}{*}{$2.234 \pm 0.012$} \\
\hline & 0.628 & & & \\
\hline & 0.631 & & & \\
\hline \multirow{3}{*}{ B } & 1.165 & \multirow{3}{*}{$1.179 \pm 0.010$} & \multirow{3}{*}{278.7} & \multirow{3}{*}{$4.685 \pm 0.009$} \\
\hline & 1.184 & & & \\
\hline & 1.187 & & & \\
\hline \multirow{3}{*}{$\mathrm{C}$} & 1.175 & \multirow{3}{*}{$1.183 \pm 0.006$} & \multirow{3}{*}{279.75} & \multirow{3}{*}{$4.703 \pm 006$} \\
\hline & 1.184 & & & \\
\hline & 1.190 & & & \\
\hline
\end{tabular}

* triplicate measurement.

Square wave voltammograms of $\mathrm{pH} 7$ PBS containing a mixture of $1 \mathrm{mM} \mathrm{UA}$ and $1 \mathrm{mM} \mathrm{AA}$ at deposition potentials in the range $-200 \mathrm{mV}$ and $+250 \mathrm{mV}$ and deposition time of $10 \mathrm{~s}$ are presented in Figure 8(a). The maximum peak current was recorded at an accumulation potential $\left(\mathrm{E}_{\mathrm{acc}}\right)$ of $-100 \mathrm{mV}$ (Inset of Figure 8(a)) and hence was taken as the optimum deposition potential.

Similarly, the peak current increased with increasing deposition time (Inset of Figure 8(b)) through the entire range of studied time. As a compromise between the enhanced peak current and accompanied analysis time, deposition time of $30 \mathrm{~s}$ where the slope of change has declined (Inset of Figure 8(b)) was selected as the optimum deposition time for further experiment.

3.5.2. Analytical Performance of the Method under the Optimized Conditions. Adsorptive anodic stripping square wave voltammograms (AdsASSWVs) of FeZ-G/GCE in pH 7 PBS containing various concentrations of UA are presented in Figure 9. The oxidative peak current showed linear dependence on the concentration of UA in the range 1.0 to $120 \mu \mathrm{M}$ with determination coefficient $\left(\mathrm{R}^{2}\right)$ and $\operatorname{LoD}(3 \mathrm{~s} / \mathrm{m}$ for $\mathrm{n}=6)$ of 0.9976 (Inset of Figure 9) and $0.06 \mu \mathrm{M}$, respectively.

3.5.3. Analytical Applications. Iron doped zeolite/graphite composite modified GCE (FeZ-G/GCE) was applied for the direct determination of uric acid in urine samples collected from three young volunteers. Although triplicate voltammograms were recorded for each analyzed urine sample, one selected voltammogram for each urine sample is presented in Figure 10. The mean UA content of the urine samples calculated in mg per $100 \mathrm{~mL}$ of human urine is thus summarized in Table 1. As can be seen from the table, while the UA content of the samples from volunteers " $\mathrm{B}$ " and " $\mathrm{C}$ " is in the range for a healthy male (3.4 to $7.0 \mathrm{mg} \mathrm{UA} / 100 \mathrm{~mL}$ urine sample), the UA content in the urine collected from the third volunteer " $\mathrm{A}$ " which was originally transparent relative to the others is below the range.

3.5.4. Validation of the Developed Method. The developed method was validated using the precision between replicate measurements, recovery results for spiked UA in human 


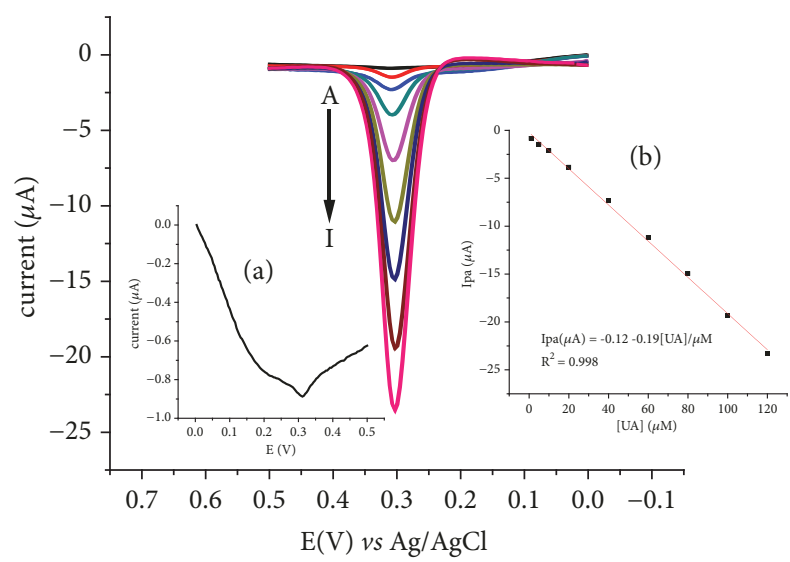

FIgUre 9: AdsASSWVs of FeZ-G/GCE in pH 7 PBS of various concentrations of UA (A-I: 1, 5, 10, 20, 40, 60, 80, 100, and $120 \mu \mathrm{M}$, respectively). Inset: (a) amplified voltammogram for $1 \mu \mathrm{M}$ UA and (b) plot of oxidative peak current of UA against concentration of UA. Experimental conditions: $\mathrm{E}_{\mathrm{acc}}=-100 \mathrm{mV} ; \mathrm{t}_{\mathrm{acc}}=30 \mathrm{~s}$; frequency $=15 \mathrm{~Hz}$; amplitude $=25 \mathrm{mV}$; and potential step $=4 \mathrm{mV}$.

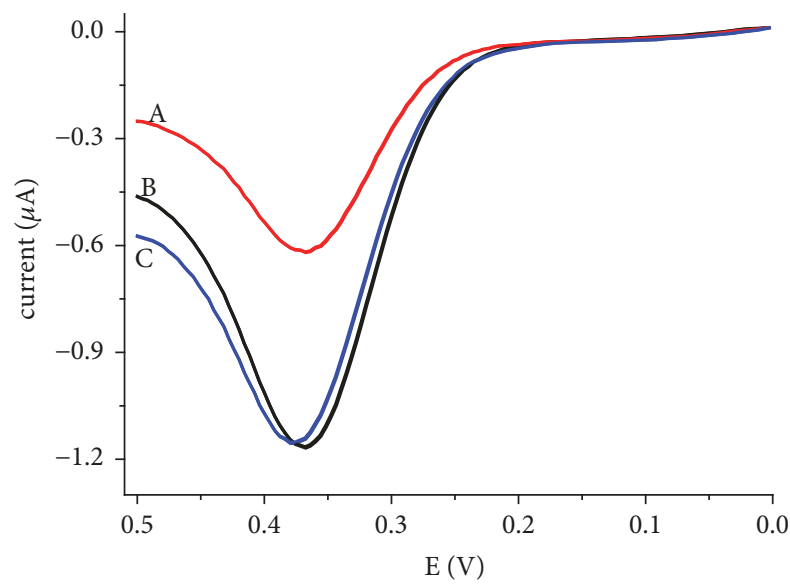

Figure 10: Selected AdsASSWVs of FeZ-G/GCE in $50 \mathrm{~mL}$ of $\mathrm{pH} 7$ PBS containing $1 \mathrm{~mL}$ of centrifuged human urine sample collected from volunteers $\mathrm{A}, \mathrm{B}$, and $\mathrm{C}$, respectively.

urine sample, and selectivity of the method for UA in the presence of AA.

$1 \mathrm{~mL}$ of centrifuged human urine (volunteer A) was added to each of three $50 \mathrm{~mL}$ flasks. While one flask was filled up to the mark with $\mathrm{pH} 7 \mathrm{PBS}$, the remaining were spiked one with 3.5 and the other with $7.0 \mu \mathrm{M}$ standard UA and finally triplicate voltammograms were recorded for each solution. Figure 11 presents representative voltammogram for the unspiked (curve a) and spiked (curves b and c) urine solutions, whereas the recovery results are summarized in Table 2. Two important observations from the present study are excellent recovery results in the range 96.61 to $103.45 \%$ and very low RSD values ( 0.002 to 0.005$)$ showing the validity of the method for determination of UA in unfiltered human urine with a complex matrix.

To further validate the method, the selectivity of the composite modified electrode for UA was checked. Figure 12

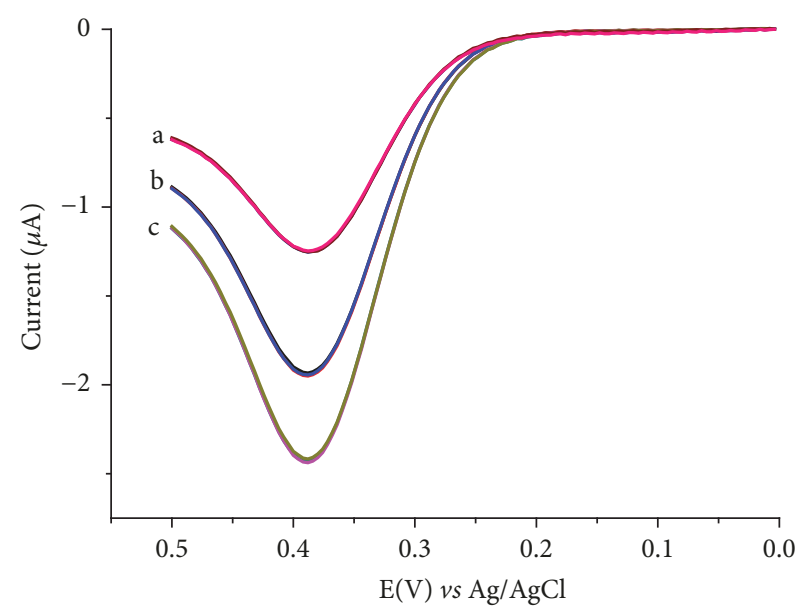

FIGURE 11: Representative AdsASSWVs of FeZ-G/GCE in pH 7.0 PBS containing (a) unspiked human urine sample, (b) human urine sample spiked with $3.5 \mu \mathrm{M}$ standard UA, and (c) human urine sample spiked with $7.0 \mu \mathrm{M}$ standard UA.

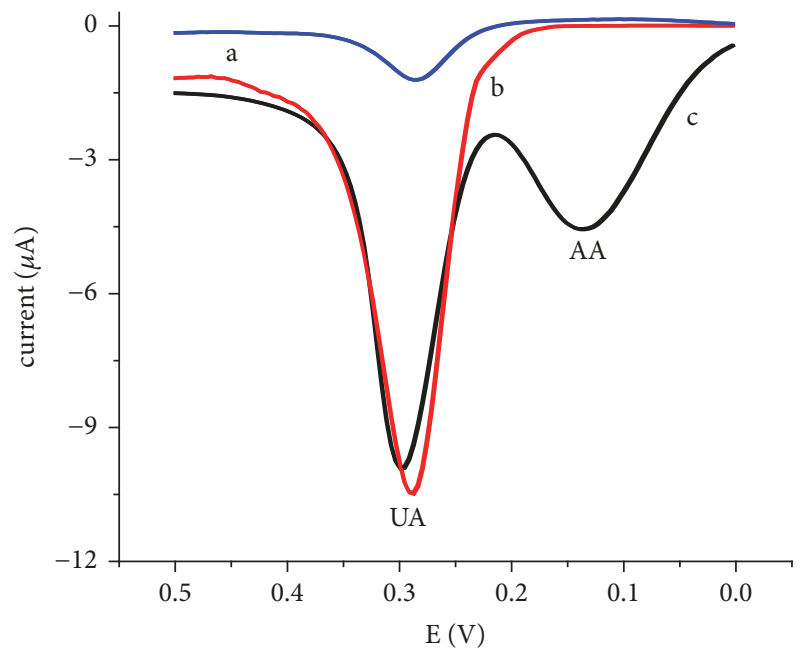

Figure 12: AdsASSWVs of FeZ-G/GCE in pH 7.0 PBS containing human urine solution (a) unspiked, (b) spiked with $50 \mu \mathrm{M} \mathrm{UA}$, and (c) b $+50 \mu \mathrm{M}$ AA.

presents voltammograms of the composite modified electrode in both unspiked and spiked human urine samples. As can be observed from the voltammograms, the presence of AA caused the signal of the UA spiked human urine to decrease only by $4.2 \%$ confirming the selectivity of the method for UA and hence validating its applicability.

\section{Conclusion}

The developed iron (III) impregnated zeolite-graphite powder composite modified glassy carbon electrode (FeZG/GCE) was characterized using electrochemical impedance spectroscopy and cyclic voltammetry. Investigation of the electrochemical behavior of UA at the surface of the developed composite modified electrode revealed an irreversible 
TABLE 2: Summary of the recovery analysis of 3.5 and $7.0 \mu \mathrm{M}$ UA in human urine (1:49 volume ratio of centrifuged urine to pH 7 PBS).

\begin{tabular}{lccc}
\hline $\begin{array}{l}\text { UA in unspiked urine } \\
\text { solution }(\mathrm{mg} / 50 \mathrm{~mL})^{*}\end{array}$ & $\begin{array}{c}\text { Added } \\
(\mathrm{mg} \mathrm{UA} / 50 \mathrm{~mL})^{* *}\end{array}$ & $\begin{array}{c}\text { Found }(\mathrm{mg} \mathrm{UA} / 50 \mathrm{~mL} \\
\text { urine solution })^{* * *}\end{array}$ & $\begin{array}{c}\text { Percent recovery } \\
(\%)\end{array}$ \\
\hline $0.060 \pm 0.002$ & 0.029 & $0.090 \pm 0.003$ & $103.45 \%$ \\
\hline
\end{tabular}

* curve $\mathrm{a} ; * *$ curve $\mathrm{b} ; \& * * *$ curve $\mathrm{c}$.

oxidation at a reduced overpotential compared to at bare glassy carbon electrode indicating the catalytic property of the modifier towards oxidation of UA. Contrary to the electrochemical behavior of uric acid at the previously reported works, uric acid exhibited a reduction peak at the present electrode. The method using composite modified electrode was validated for its applicability for determination of UA in human urine samples. The oxidative current of UA at the surface of the electrode showed linear dependence on concentration in a reasonably wide range of concentration with a very good correlation coefficient value. The uric acid content of human urine samples collected from three male volunteers was found to be about the recommended level for healthy males. Excellent recovery and low interference results and normal uric acid content of the assessed urine samples added to the wide linear dynamic range validated the method for determination of uric acid in complex matrix systems like urine.

\section{Data Availability}

All the generated cyclic and square wave voltammetric data used in this study (Electrochemical characterization of Iron (III) doped zeolite-graphite composite modified glassy carbon electrode and its application for AdsASSWV determination of uric acid in human urine) have been fully interpreted and are included within the article. Thus, anybody who wishes to use the data can use it following the publisher guideline.

\section{Conflicts of Interest}

The author declares that he has no conflicts of interest.

\section{References}

[1] F. Roch-Ramel and B. Guisan, "Renal transport of urate in humans," Physiology Journal, vol. 14, no. 2, pp. 80-84, 1999.

[2] B. Álvarez-Lario and J. Macarrón-Vicente, "Uric acid and evolution," Rheumatology, vol. 49, no. 11, pp. 2010-2015, 2010.

[3] T. Mikami and M. Sorimachi, "Uric acid contributes greatly to hepatic antioxidant capacity besides protein," Physiological Research, vol. 66, pp. 1001-1007, 2017.

[4] A. Podlecka Pietowska, J. Przybek, K. Chorazka, M. Nojszewska, B. Z. Pniewska, and A. Kaminska, "Assessment of serum uric acid levels in multiple sclerosis during diseasemodifying treatment," Journal of Multiple Sclerosis, vol. 5, no. 1, pp. 1-3, 2018.

[5] C. Ruggiero, A. Cherubini, A. Ble et al., "Uric acid and inflammatory markers," European Heart Journal, vol. 27, no. 10, pp. 1174-1181, 2006.
[6] J.-H. Chen, S.-Y. Chuang, H.-J. Chen, Y. E. H. Wen-Ting, and P. A. N. Wen-Harn, "Serum uric acid level as an independent risk factor for all-cause, cardiovascular, and ischemic stroke mortality: a chinese cohort study," Arthritis Care \& Research, vol. 61, no. 2, pp. 225-232, 2009.

[7] J. Markelj, T. Zupančič, and B. Pihlar, "optimization of high performance liquid chromatography method for simultaneous determination of some purine and pyrimidine bases," Acta Chimica Slovenica, vol. 63, no. 1, pp. 8-17, 2016.

[8] K. C. Honeychurch, "The determination of uric acid in human saliva by liquid chromatography with electrochemical detection," Journal of Analytical, Bioanalytical and Separation Techniques, vol. 2, no. 1, pp. 47-51, 2017.

[9] Q. C. Chu, M. Lin, C. H. Geng, and J. N. Ye, "Determination of uric acid in human saliva and urine using miniaturized capillary electrophoresis with amperometric detection," Chromatographia, vol. 65, no. 3-4, pp. 79-184, 2007.

[10] S. Zhao, J. Wang, F. Ye, and Y. Liu, "Determination of uric acid in human urine and serum by capillary electrophoresis with chemiluminescence detection," Analytical Biochemistry, vol. 378, no. 2, pp. 127-131, 2008.

[11] S. M. U. Ali, Z. H. Ibupoto, M. Kashif, U. Hashim, and M. Willander, "A potentiometric indirect uric acid sensor based on $\mathrm{ZnO}$ nanoflakes and immobilized uricase," Sensors, vol. 12, no. 3, pp. 2787-2797, 2012.

[12] H. H. Hamzah, Z. M. Zain, N. L. M. Musa, Y. C. Lin, and E. Trimbee, "Spectrophotometric determination of uric acid in urine based-enzymatic method uricase with 4-aminodiphenylamine diazonium sulfate (variamine blue RT salt)," Journal of Analytical and Bioanalytical Techniques, vol. S7, pp. 1-6, 2013.

[13] F. Arslan, "An amperometric biosensor for uric acid determination prepared from uricase immobilized in polyanilinepolypyrrole film," Sensors, vol. 8, no. 9, pp. 5492-5500, 2008.

[14] X. Huang, H. Im, O. Yarimaga et al., "Direct electrochemistry of uric acid at chemically assembled carboxylated single-walled carbon nanotubes netlike electrode," The Journal of Physical Chemistry B, vol. 110, no. 43, pp. 21850-21856, 2006.

[15] Y. Zhao, J. Bai, L. Wang et al., "Simultaneous electrochemical determination of uric acid and ascorbic acid using L-cysteine self-assembled gold electrode," International Journal of Electrochemical Science, vol. 1, pp. 363-371, 2006.

[16] S. Rajendrachari, B. E. Kumara Swamy, S. Reddy, and D. Chaira, "Synthesis of silver nanoparticles and their applications," Analytical \& Bioanalytical Electrochemistry, vol. 5, no. 4, pp. 455466, 2013.

[17] D. Sun, Y. Zhang, F. Wang, K. Wu, J. Chen, and Y. Zhou, "Electrochemical sensor for simultaneous detection of ascorbic acid, uric acid and xanthine based on the surface enhancement effect of mesoporous silica," Sensors and Actuators B: Chemical, vol. 141, no. 2, pp. 641-645, 2009.

[18] K. Movlaee, P. Norouzi, H. Beitollahi, M. Rezapour, and B. Larijani, "Highly selective differential pulse voltammetric determination of uric acid using modified glassy carbon electrode," 
International Journal of Electrochemical Science, vol. 12, no. 4, pp. 3241-3251, 2017.

[19] S. K. Ponnaiah, P. Periakaruppan, and B. Vellaichamy, "New electrochemical sensor based on a silver-doped iron oxide nanocomposite coupled with polyaniline and its sensing application for picomolar-level detection of uric acid in human Blood and Urine Samples," The Journal of Physical Chemistry B, vol. 122, no. 12, pp. 3037-3046, 2018.

[20] T. Rohani and M. A. Taher, "Novel functionalized multiwalled carbon nanotube-glassy carbon electrode for simultaneous determination of ascorbic acid and uric acid," Arabian Journal of Chemistry, vol. 11, no. 2, pp. 214-220, 2018.

[21] M. M. Ardakani, Z. Akrami, H. Kazemian, and H. Zare, "Electrocatalytic characteristics of uric acid oxidation at graphitezeolite-modified electrode doped with iron (III)," Journal of Electroanalytical Chemistry, vol. 586, no. 1, pp. 31-38, 2006.

[22] L. M. Muresan, "Zeolite-modified electrodes with analytical applications," Pure and Applied Chemistry, vol. 83, no. 2, pp. 325-343, 2010.

[23] M. Noroozifar, M. Khorasani-Motlagh, R. Akbari, and M. Bemanadi Parizi, "Simultaneous and sensitive determination of a quaternary mixture of AA, DA, UA and Trp using a modified GCE by iron ion-doped natrolite zeolite-multiwall carbon nanotube," Biosensors and Bioelectronics, vol. 28, no. 1, pp. 56-63, 2011.

[24] L. Yang, D. Liu, J. Huang, and T. You, "Simultaneous determination of dopamine, ascorbic acid and uric acid at electrochemically reduced graphene oxide modified electrode," Sensors and Actuators B: Chemical, vol. 193, pp. 166-172, 2014. 

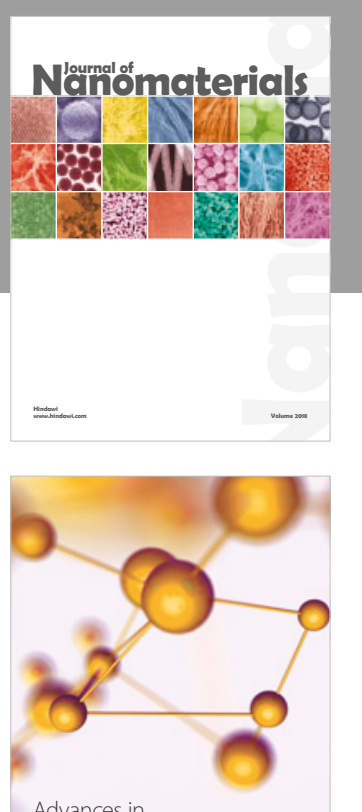

Physical Chemistry
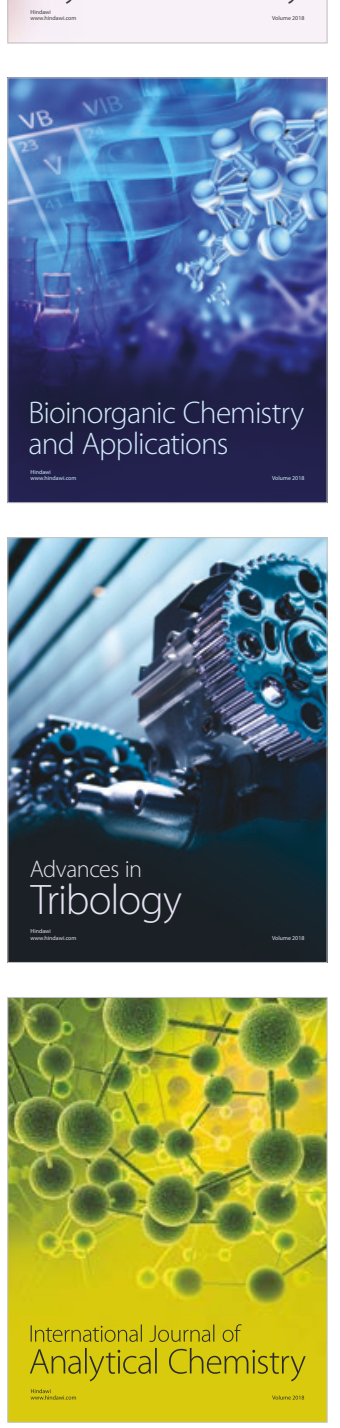

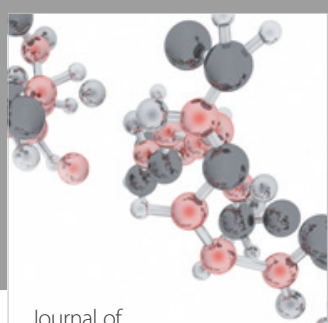

Analytical Methods

in Chemistry

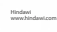

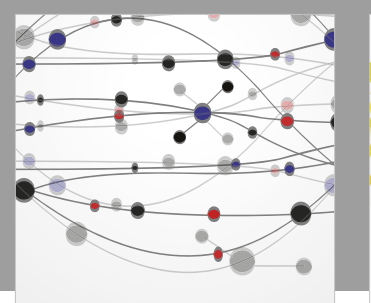

The Scientific World Journal

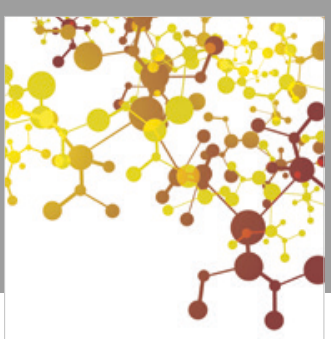

Journal of

Applied Chemistry
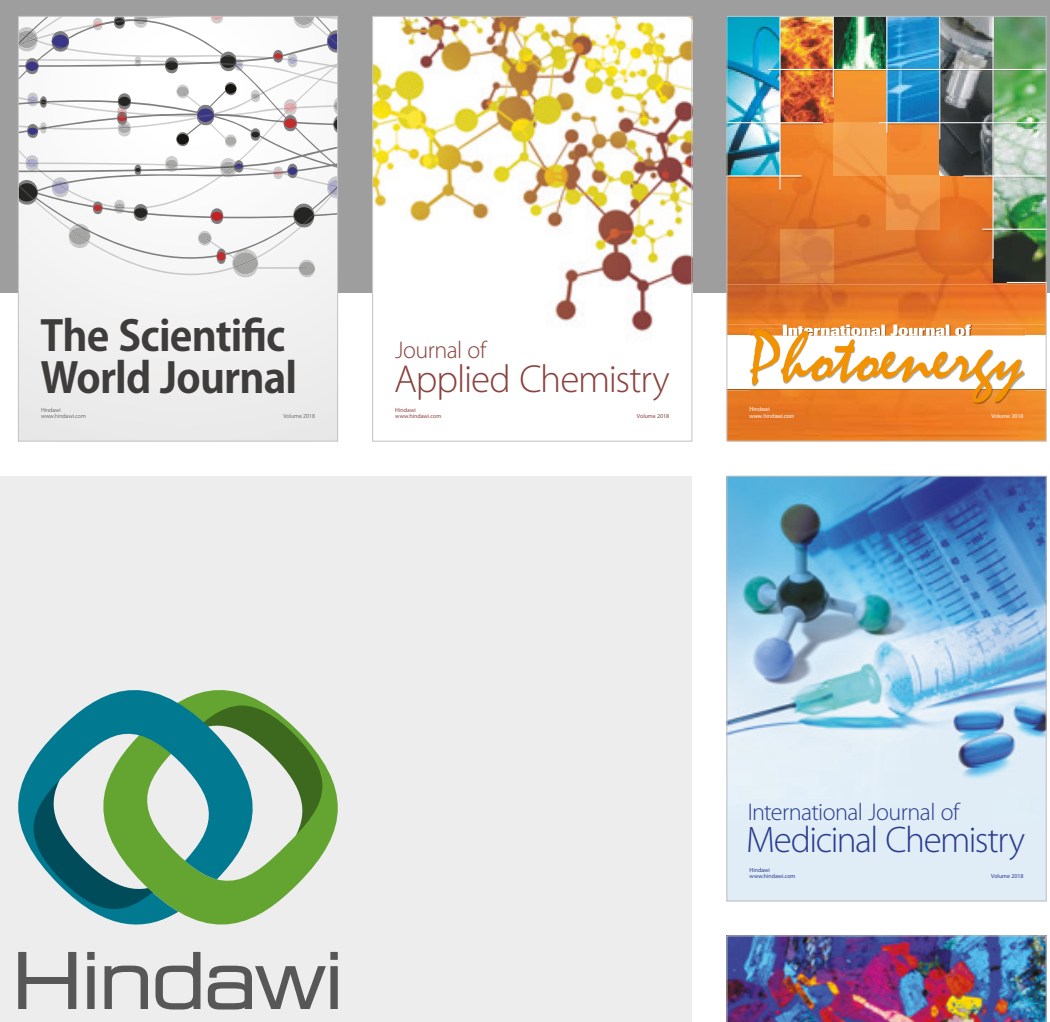

Submit your manuscripts at

www.hindawi.com
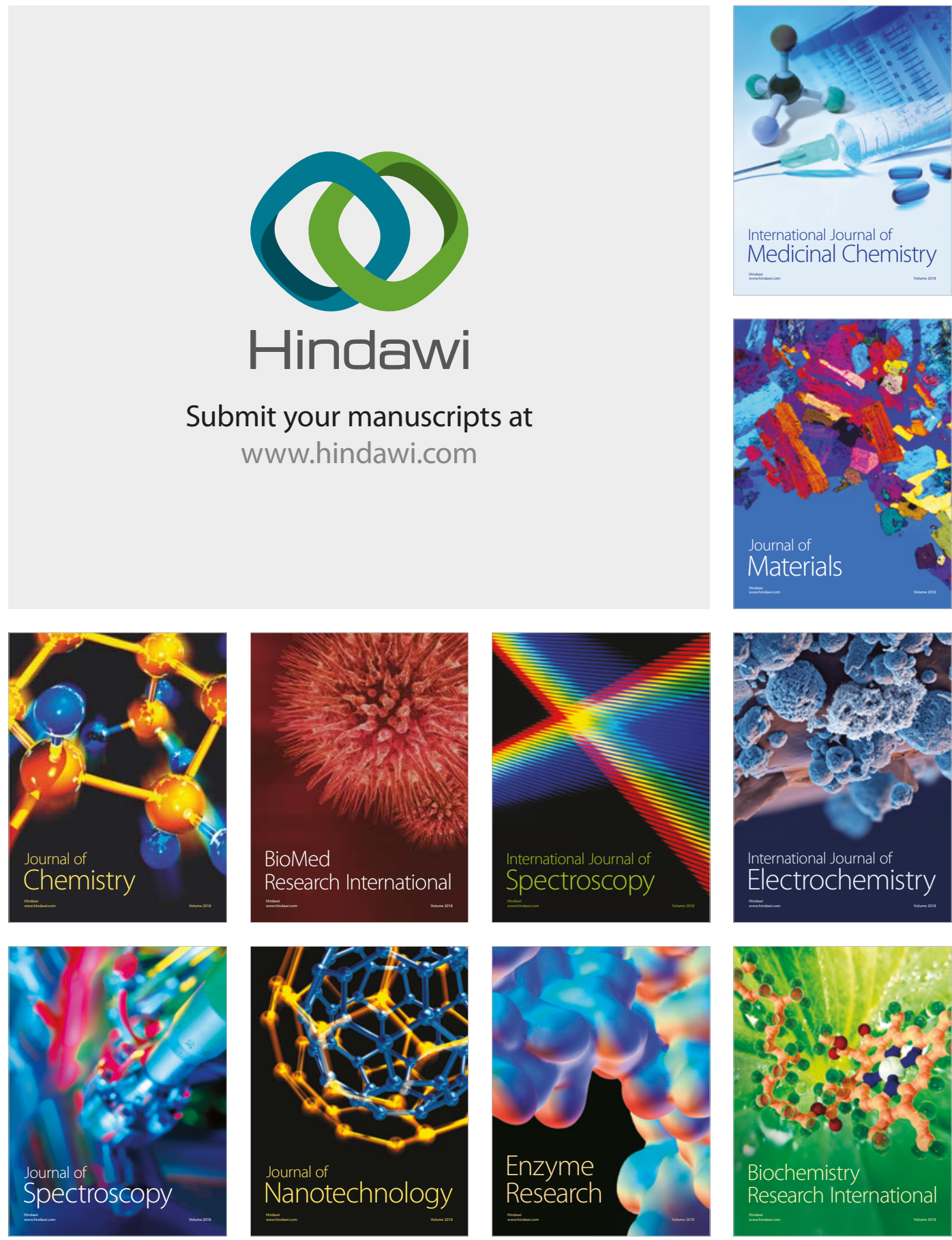
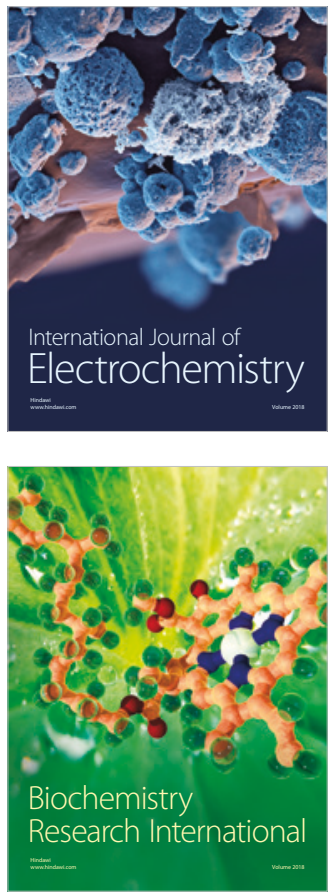